REVIEW

\title{
Effectiveness of extracorporeal shock wave therapy for tennis elbow (lateral epicondylitis)
}

\author{
D Stasinopoulos, M I Johnson
}

Br J Sports Med 2005;39:132-136. doi: 10.1136/bjsm.2004.015545

Randomised controlled trials were reviewed to evaluate the evidence of the effectiveness of extracorporeal shock wave therapy in the management of tennis elbow. Seven relevant trials were found, which had satisfactory methodology but conflicting results. Further research with well designed randomised control trials is needed to establish the absolute and relative effectiveness of this intervention for tennis elbow.

See end of article for authors' affiliations

Correspondence to: D Stasinopoulos, Rheumatology and Rehabilitation Centre, Orfanidou 16, Patissia, Athens 11141, Greece; d_stasinopoulos@ yahoo.gr

Accepted

10 November 2004 ateral epicondylitis or tennis elbow is one of the most common lesions of the arm. This -injury is a major challenge, as it is difficult to treat, prone to recurrence, and may last for several weeks or months, with the average duration of a typical episode reported to be between six months and two years. ${ }^{1}$

Tennis elbow is defined as pain on the facet of the lateral epicondyle, which is reproduced by digital palpation on the above site, resisted wrist extension, resisted middle finger extension, and gripping. $^{2-4}$ The dominant arm is commonly affected, with a prevalence of $1-3 \%$ in the general population, but this increases to $19 \%$ in 30-60 year olds and appears to be more long standing and severe in women. ${ }^{35-8}$ It is generally a work related or sport related disorder of the caused by excessive, quick, monotonous, repetitive movements of the wrist, especially in eccentric contractions and gripping activities causing macroscopic and microscopic tears in the extensor carpi radialis brevis tendon, the most commonly affected structure. ${ }^{36-12}$ It is a degenerative or failed healing tendon response characterised by the increased presence of fibroblasts, increased amounts of proteoglycans and glycosaminoglycans, vascular hyperplasia, and disorganised collagen in the origin of the extensor carpi radialis brevis tendon. ${ }^{13-19}$ The diagnosis is simple and confirmed by tests that can be used in daily clinical practice such as palpation on the facet of the lateral epicondyle, the Tomsen test, handgrip dynamometer testing, Mill's test, chair test, and the coffee cup test. ${ }^{20-26}$

Although the diagnosis of this condition is simple and easy, its management is difficult. Conservative treatment is the primary choice, but a plethora of interventions, medical and physiotherapeutic with different theoretical mechanisms of action, have been reported, all with the single aim of reducing pain and improving functional status. However, such a variety of treatment options suggests that the optimal
L common extensor origin of the arm, usually management strategy is not known, and more research to discover the most effective treatment is needed.

Extracorporeal shock wave therapy (ESWT) is a recently introduced modality for the management of tennis elbow. Its effectiveness has been evaluated in a review, ${ }^{27}$ but conclusions, positive or negative, cannot be drawn from this review because of the small number of studies included. As it is the only systematic review of the effectiveness of ESWT in the management of tennis elbow based on literature published until 2002, and several new randomised controlled trials (RCTs) have been published since then, an updated systematic review seemed to be indicated. Therefore the aim of this article was to determine the effectiveness of ESWT in the management of tennis elbow and to provide recommendations based on this evidence.

\section{METHODS}

\section{Search strategy}

Computerised searches were performed using Medline (from 1966 to August 2004), Embase (from 1988 to August 2004), Cinahl (from 1982 to August 2004), Index to Chiropractic Literature (from 1992 to August 2004), Chirolars (from 1994 to August 2004) and SportsDiscus (from 1990 to August 2004) databases. Only English language publications were considered. The following search terms "tennis elbow", "lateral epicondylitis", "lateral epicondylalgia", "rehabilitation", "extracorporeal shock wave therapy", "management", "clinical trials", and "randomised control trials" were used individually or in various combinations. Other references were identified from existing reviews and other papers cited in the publications searched. Further citations were sought from the reference sections of papers retrieved, from contacting experts in the field, and from the Cochrane Collaboration (last search July 2004), an international network of experts who search journals for relevant citations. Unpublished reports and abstracts were not considered. Keywords and search strategy were selected by the researcher only, without the help of an expert librarian with experience in searching databases to computerised health literature.

\section{Selection of studies}

To be included within the review, studies had to fulfil the following conditions: it had to be a RCT, with or without follow up, which included

Abbreviations: ESWT, extracorporeal shock wave therapy; RCT, randomised control trial 
Table 1 Evaluation form A, adapted from Chalmers et al, ${ }^{28}$ showing the 15 items scored to evaluate the study design of a clinical trial

\begin{tabular}{ll}
\hline Items & Possible points \\
\hline Description of selection of subject was adequate & $0-3$ \\
Description of patients screened was provided & $0-3$ \\
Inclusion criteria for study included & $0-2$ \\
Exclusion criteria for study included & $0-2$ \\
Withdrawals and reason for withdrawal were & $0-3$ \\
described & $0-3$ \\
Therapeutic regimen definition & $0-2$ \\
Control appearance & $0-10$ \\
Randomisation was blinded & $0-8$ \\
Patients were blinded to treatment group & $0-8$ \\
Investigators were blinded to treatment group & $0-4$ \\
Power calculations (sample size requirements) & $0-4$ \\
Adequacy of randomisation was evaluated & $0-3$ \\
Adequacy of blinding was evaluated & $0-3$ \\
Compliance with treatment was assessed & $0-2$ \\
Measure of outcome of active therapy was made & \\
\hline The total possible score is 60. & \\
\hline
\end{tabular}

subjects aged 18 and above treated for tennis elbow. The treatment had to be any type of ESWT evaluated against at least one of the following: (a) placebo; $(b)$ no treatment; (c) another treatment, conservative (physical therapy intervention or medical) or operative. RCTs in which the ESWT was given as part of the treatment-for example, nonsteroidal anti-inflammatory drugs and ESWT or ultrasound and exercise programme and ESWT-were excluded, because we would not know how each modality contributed to the results. However, the effectiveness of these management strategies has not been assessed in the literature. Data were sought for one of the following four primary outcome measures: pain (scales or descriptive words), function (scales, tests, or descriptive words), grip strength (pain-free or maximum), and a global measure (overall improvement, proportions of patients recovered, subjective improvement of symptoms).

The titles and abstracts of all studies were assessed for the above eligibility criteria. If it was absolutely clear from information provided in the title and/or abstract that the study was not relevant, it was excluded. If it was unclear from the available abstract and/or the title, the full text article was retrieved. There was no blinding to study author, place of publication, or results. The researcher assessed the content of all full text articles, making the selection criteria.

\section{Methodological quality}

The quality of the selected papers was examined using the system proposed by Chalmers et al, ${ }^{28}$ with some minor modifications, which evaluates the design and conduct of the research by scoring the quality. According to Labelle et $a l,{ }^{29}$ it is possible to interpret the results appropriately using this system, especially when there are conflicting results between two studies, or studies with small sample size and inconclusive results.

The Chalmers' technique consists of two evaluation forms with 29 individually scored items, allowing a maximum score of 100. The first form examines the study design, giving particular importance to blinding of patients and doctors, and the presence and method of randomisation of the patients and doctors when applicable (table 1). The second form evaluates the quality of the data analysis, the statistical analysis, and the presentation of results (table 2).

This system has been applied to several therapeutic trials, and an arbitrary score of $70 \%$ is considered to be the minimum required for a high quality design for controlled
Table 2 Evaluation form B adapted from Chalmers et a ${ }^{28}$ showing the 14 items scored to evaluate the data analysis of a clinical trial

\begin{tabular}{ll}
\hline Items & Possible points \\
\hline Dates of study description & $0-2$ \\
Results of randomisation & $0-2$ \\
Post type 2 estimate & $0-3$ \\
Confidence limits & $0-3$ \\
Time series analysis & $0-2$ \\
Timing of evens & $0-4$ \\
Correlation & $0-2$ \\
Statistical analysis & $0-4$ \\
p Value & $0-2$ \\
Withdrawals & $0-4$ \\
Handling withdrawals & $0-4$ \\
Side effects & $0-2$ \\
Retrospective evaluation & $0-3$ \\
Presentation of results & $0-3$ \\
\hline The total possible score is 40. &
\end{tabular}

therapeutic trials. If the score is below $40 \%(0-39)$, the design of the study is low quality, and, if it is $40-69 \%$, it is satisfactory. ${ }^{29}$

\section{Data abstraction}

Raw data on means for all outcomes, as well as the authors' report of the study results, were extracted from the full manuscripts by the reviewer. Data on adverse events were abstracted from the studies.

Basic data were extracted including characteristics of participants (age, sex, previous treatments, and duration of disorder), outcomes (type of outcome measure and instrument), and interventions (type, dose or intensity, frequency, and duration).

\section{RESULTS}

\section{Trial flow}

From the initial examination of citations, yielded from the literature search, 12 studies were included. After review of the completed texts, five studies were excluded, ${ }^{30-34}$ leaving seven eligible RCTs, to be included in the review. ${ }^{35-41}$ No additional eligible RCTs were found by screening the references.

\section{Description of studies}

Four studies ${ }^{35} 373841$ explicitly excluded patients with concomitant neck, thorax, or shoulder complaints, and the rest $^{363940}$ excluded only patients with concomitant neck or thorax complaints.

All studies except Rompe et $a l^{40}$ and Melegati et $a l^{41}$ performed a short term outcome assessment (four to six weeks after the end of treatment). Five studies 35 37 39-41 included a long term follow up (six months or more after the end of treatment).

In all studies, the study population consisted of subjects of both sexes over a wide range of ages suffering from tennis elbow.

Pain and function were the primary outcome measures for all studies. Pain was measured in all studies either by visual analogue scales, ordinal scales from 3 to 9 points, or descriptive words. Function had also been measured in all studies except those of Speed $e a^{36}$ and Crowther et $^{3 l^{38}}$ either by visual analogue scales, questionnaire, or tests such as the lifting test. Other outcome measures were grip strength and global improvement or patient satisfaction. Grip strength was reported in all studies, except those of Speed et al, ${ }^{36}$ Crowther et $a l_{,}{ }^{38}$ and Melegati et al. ${ }^{41}$ Grip strength was measured as maximum grip strength ${ }^{40}$ in one study, and three studies did 
Table 3 Results for seven papers on treatment by extracorporeal shock wave therapy (ESWT)

\begin{tabular}{|c|c|c|c|c|c|}
\hline Reference & No & Method of treatment & Outcome measures & Conclusions & Quality score (\%) \\
\hline Rompe et $\alpha^{\beta 5}$ & 100 & ESWT $v$ sham therapy & $\begin{array}{l}\text { Pain } \\
\text { Function } \\
\text { Grip strength } \\
\text { Global improvement }\end{array}$ & $\begin{array}{l}\text { ESWT was more effective than } \\
\text { sham therapy at the end of } \\
\text { treatment and at the follow ups }\end{array}$ & 55 \\
\hline Haake et $a l^{\beta 7}$ & 271 & ESWT $v$ sham therapy & $\begin{array}{l}\text { Pain } \\
\text { Function } \\
\text { Grip strength } \\
\text { Global improvement }\end{array}$ & $\begin{array}{l}\text { No difference after the end of } \\
\text { treatment and at the follow ups }\end{array}$ & 75 \\
\hline Speed et $a^{\beta 6}$ & 75 & ESWT $v$ sham therapy & $\begin{array}{l}\text { Pain } \\
\text { Global improvement }\end{array}$ & $\begin{array}{l}\text { No difference after the end of } \\
\text { treatment and at the follow ups }\end{array}$ & 53 \\
\hline Crowther ef $a l^{\beta 8}$ & 73 & ESWT $v$ steroid injection & Pain & $\begin{array}{l}\text { Injection more effective than } \\
\text { ESWT at the end of treatment } \\
\text { and at the follow up }\end{array}$ & 56 \\
\hline Melikyan ef $a^{\beta 9}$ & 74 & ESWT $v$ sham therapy & $\begin{array}{l}\text { Pain } \\
\text { Function } \\
\text { Grip strength } \\
\text { Global improvement }\end{array}$ & $\begin{array}{l}\text { No difference after the end of } \\
\text { treatment and at the follow ups }\end{array}$ & 57 \\
\hline Rompe et a ${ }^{\mu 0}$ & 78 & ESWT $v$ sham therapy & $\begin{array}{l}\text { Pain } \\
\text { Function } \\
\text { Grip strength } \\
\text { Global improvement }\end{array}$ & $\begin{array}{l}\text { ESWT was more effective than } \\
\text { sham therapy at the end of } \\
\text { treatment and at the follow ups }\end{array}$ & 74 \\
\hline Melegati et $\left.a\right|^{\mu 1}$ & 41 & $\begin{array}{l}\text { Lateral ESWT technique } \\
v \text { back ESWT technique }\end{array}$ & $\begin{array}{l}\text { Pain } \\
\text { Function } \\
\text { Global improvement }\end{array}$ & $\begin{array}{l}\text { No differences between the two } \\
\text { techniques at the end of the } \\
\text { treatment and at the follow up. } \\
\text { Improvement for both from } \\
\text { baseline }\end{array}$ & 45 \\
\hline
\end{tabular}

not specify the way that grip strength was measured. ${ }^{35}{ }^{37}{ }^{39} \mathrm{~A}$ great variety of outcome measures were used to describe global improvement or patient satisfaction. Crowther et $a l^{38}$ and Speed $e a^{36}$ did not report global improvement or patient satisfaction.

Almost all studies apart from that of Melegati et $a l^{41}$ had adequate blinded outcome assessors. Three studies gave enough details in relation to the blinding of patients and therapists. ${ }^{37} 3941$

Four studies had used a proper method of randomisation, ${ }^{37} 384041$ whereas the rest did not clearly describe the randomisation process.

All studies reported dropouts and the reasons. Side effects were also reported in all studies.

The sample size of the studies ranged between $20-21^{41}$ and $136-137^{37}$ patients per intervention group. Only two studies stated the power calculations for the sample size. ${ }^{37} 40$

\section{Effectiveness}

Table 3 gives our evaluation for the seven clinical trials, expressing the results as percentages of the maximum possible score and allowing for items which were not applicable to every study and were therefore excluded from the calculations. The average score for the seven trials was $59.2 \%$, with a minimum of $45 \%$ for the weakest study design $^{41}$ and a maximum of $75 \%$ for the strongest one. ${ }^{37}$ All studies had a satisfactory quality design.

Five out of seven studies compared ESWT with sham therapy. ${ }^{35-37} 3940$ Two satisfactory quality studies $^{36}{ }^{39}$ and a high quality study ${ }^{37}$ revealed that ESWT was no more effective than sham therapy in treating tennis elbow. On the other hand, positive effects of ESWT in the management of tennis elbow showed a satisfactory quality study ${ }^{35}$ and a high quality study. ${ }^{40}$ Moreover, a satisfactory quality study, comparing steroid injection with ESWT, found the injection was more effective than the ESWT in the management of tennis elbow. ${ }^{38}$ Finally a satisfactory quality study comparing two techniques of ESWT (lateral and back) in the management of tennis elbow found no differences between them, but improvement in relation to the baseline. ${ }^{41}$

\section{DISCUSSION}

In this review, the effectiveness of ESWT was assessed by searching databases in combination with reference checking for randomised controlled clinical trials. It is the first to include a satisfactory number of studies that assessed the effectiveness of ESWT in the management of tennis elbow. Conflicting results were found.

ESWT is a relatively new treatment recently introduced for managing common tendon problems such as tennis elbow with the aim to produce analgesia, although the mechanism of analgesia remains the same. It has been used for years as the standard treatment for disintegrating kidney stones. ${ }^{33}$ Although we found conflicting results on its effectiveness in the management of tennis elbow, it cannot be ruled out from research, as it is a dose-response modality and the optimal treatment dose has obviously not yet been discovered. It was our intention to carry this out as a dose-response analysis. However, it was difficult to test for a dose response, because of poor reporting of variables and a dearth of clinical studies comparing the effectiveness of different treatment modality variables. ${ }^{42}$

Two previous systematic reviews, Smidt $e t$ al $l^{43}$ and Trudel et $a_{1}{ }^{44}$ evaluated the effectiveness of physiotherapy and conservative treatments in the management of tennis elbow respectively without examining the effects of ESWT. Neither review explained why this occurred. Moreover, a systematic review of no dose response parameters was carried out in both, as we did in our review.

Although overall the quality of studies included in the review was satisfactory, there were methodological limitations. Many of the studies failed to provide adequate long term follow up, blinding, and power calculations. The use of standardised outcome measures was another area of particular deficit. Finally, the protocol of the intervention was not described in full detail, making replication difficult. Therefore well designed RCTs are needed to investigate the effectiveness of ESWT in the management of tennis elbow.

Methodological limitations of this systematic review include searching in English alone, lack of trials selection 


\section{What is already known on this topic}

ESWT is a recommended treatment for tennis elbow.

blinding, and absence of meta-analyses. However, information on the selection criteria is often missing from the methods section of an article, so blinding has to be broken to retrieve it, as there is evidence that a difference may exist between blinded and unblinded reviews. This is very time consuming, and the differences show little consistency in direction of bias or its magnitude..$^{45}$ For these reasons, we decided that the reviewer should not to be blinded to the above characteristics, even though this may have increased the possibility of methodological quality and data analysis bias. Moreover, it may sometimes be difficult for reviewers to decide whether it is clinically relevant to combine the results of a group of studies in a meta-analysis - for example, studies of patients with different types of treatment, different types of comparison groups, or different clinical characteristics of patients studied. There is consensus among the editorial board of the Cochrane Back Review Group that, if relevant valid data are lacking (data are too sparse or of too low quality) or if data are statistically and clinically too heterogeneous, a meta-analysis should be avoided and reviewers should perform a qualitative review. ${ }^{46}$ For these reasons, a qualitative review was conducted.

Finally, we conclude that research with well designed RCTs is required to provide meaningful evidence on the effectiveness of ESWT for the management of tennis elbow.

\section{Authors' affiliations}

D Stasinopoulos, Centre of Rheumatology and Rehabilitation, Athens, Greece and Department of Health and Environment, Leeds Metropolitan University, Leeds, UK

M I Johnson, Leeds Metropolitan University

Competing interests: none declared

\section{REFERENCES}

1 Murtagh J. Tennis elbow. Aust Fam Physician. 1988;17: 90, 91, 94-95)

2 Haker E. Lateral epicondylalgia: diagnosis, treatment and evaluation. Critical Reviews in Physical and Rehabilitation Medicine 1993;5:129-54.

3 Vicenzino B, Wright A. lateral epicondylalgia. I. Epidemiology, pathophysiology, aetiology and natural history. Phys Ther Rev 1996; 1:23-34

4 Assendelft W, Green S, Buchbinder R, et al. Tennis elbow. BMJ 2003;7410:327.

5 Allander $\mathbf{E}$. Prevalence, incidence and remission rates of some common rheumatic diseases and syndromes. Scand J Rheumatol 1974;3:145-53.

6 Kivi P. The etiology and conservative treatment of humeral epicondylitis. Scand J Rehabil Med 1982;15:37-41.

7 Verhaar J. Tennis elbow: anatomical, epidemiological and therapeutic aspects. Int Orthop 1994; 18:263-7

8 Hamilton P. The prevalence of humeral epicondylitis: a survey in general practice. J R Coll Gen Pract 1986;36:464-5.

9 Haahr J, Andersen J. Physical and psychological risk factors for lateral epicondylitis. Environ Med 2003;60:322-9.

10 Haahr J, Andersen J. Prognostic factors in lateral epicondylitis: a randomised trial with one year follow up in 266 new cases treated with minimal occupational intervention or the usual approach in general practice. Rheumatology 2003;42:1216-25.

11 Paoloni J, Murrell G. Identification of prognostic indicators for patients outcome in extensor tendinopathy at the elbow. Scand J Med Sci Sports 2004; 14:163-7.

12 Waugh E, Jaglal S, Davis A, et al. Factors associated with prognosis of lateral epicondylitis after 8 weeks of physical therapy. Arch Phys Med Rehabil 2004:85:308-18.

13 Nirschl R, Pettrone F. Tennis elbow: the surgical treatment of lateral epicondylitis. J Bone Joint Surg [Am] 1979:61:832-9.
What this study adds

The results of this review reveal conflicting findings about the effectiveness of ESWT in the management of tennis elbow. Further research with well designed RCTs is needed to establish its absolute and relative effectiveness.

14 Regan W, Wold E, Coonrad R, et al. Microscopic histopathology of chronic refractory lateral epicondylitis. Am J Sports Med 1992;20:746-9.

15 Verhaar J, Walenkamp G, Kester A, et al. Lateral extensor release for tennis elbow: a prospective long term follow up study. J Bone Joint Surg [Am] 1993; 75: 1034-43.

16 Potter G, Hannafin A, Morwessel M, et al. Lateral epicondylitis: correlation of MR imaging, surgical and histopathological findings. Radiology 1995; 196:43-6.

17 Teitz C, Garrett E, Miniaki A, et al. Tendon problems in athletic individuals. J Bone Joint Surg [Am] 1997;79:138-52.

18 Kraushal B, Nirschl, R. Current concepts review: tendinosis of the elbow (tennis elbow). Clinical features and findings of histological immunohistochemical and electron microscopy studies. J Bone Joint Surg [Am] 1999;81:259-85.

19 Alfredson $\mathrm{H}$, Liung $\mathrm{B}$, Thorsen $\mathrm{K}$, et al. In vivo investigation of ECRB tendons with microdialysis technique: no signs of inflammation but high amounts of glutamate in tennis elbow. Acta Orthop Scand 2000;71:475-9.

20 Gellman H. Tennis elbow (lateral epicondylitis). Orthop Clin North Am 1992;23:75-82.

21 Nirschl R. Elbow tendinosis/tennis elbow. Clin Sports Med 1992;11:851-70.

22 Noteboom T, Cruver S, Keller A, et al. Tennis elbow: A review. J Orthop Sports Phys Ther 1994; 19:357-66.

23 Plancher K, Halbrect J, Lourie G. Medial and lateral epicondylitis in the athlete. Clin Sports Med 1996;15:282-303.

24 Peters T, Baker C. Lateral epicondylitis. Clin Sports Med 2001;20:549-63.

25 Goguin J-P, Rush F. Lateral epicondylitis. What is it really? Curr Orthop 2003;17:386-9.

26 Nirschl R, Ashman E. Elbow tendinopathy: tennis elbow. Clin Sports Med 2003;22:813-36.

27 Buchbinder R, Green S, White $M$, et al. Shock wave therapy for lateral elbow pain. Cochrane Database Syst Rev 2002; 1:CD003524.

28 Chalmers TC, Smith H Jr, Blackburn B, et al. A method for assessing the quality of a randomized control trial. Control Clin Trials $1981 ; 2: 31-49$

29 Labelle H, Guibert R, Joncas J, et al. Lack of scientific evidence for the treatment of lateral epicondylitis of the elbow: an attempted meta-analysis. $J$ Bone Joint Surg [Br] 1992;74:646-51.

30 Krischek O, Hopf C, Nafe B, et al. Shock-wave therapy for tennis and golfer's elbow: 1 year follow up. Arch Orthop Trauma Surg 1999;119:62-6.

31 Maier M, Steinborn M, Schmitz C, et al. Extracorporeal shock wave therapy for chronic lateral epicondylitis: prediction of outcome by imaging. Arch Orthop Trauma Surg 2001;121:379-84.

32 Rompe J, Riedel C, Betz U, et al. Chronic lateral epicondylitis of the elbow (tennis elbow): prospective comparison of low energy wave therapy with low energy shock wave therapy plus manual therapy of the cervical spine. Arch Phys Med Rehabil 2001;82:578-82.

33 Haake $M$, Boddeker I, Decker T, et al. Side-effects of extracorporeal shock wave therapy (ESWT)in the treatment of tennis elbow. Arch Orthop Trauma Surg 2002;122:222-8.

34 Wang $\mathrm{C}$, Chen $\mathrm{H}$. Shock wave therapy for patients with lateral epicondylitis of the elbow: a one to two year follow up. Am J Sports Med 2002;30:422-5.

35 Rompe J, Hopf C, Kullmer K, et al. Analgesic effects of extracorporeal shock wave therapy on chronic tennis elbow. J Bone Joint Surg [Br] 1996;78:233-7.

36 Speed C, Nichols D, Richards C, et al. Extracorporeal shock wave therapy for lateral epicondylitis: a double blind randomized controlled trial. J Orthop Res 2002;20:895-8.

37 Haake M, Konig I, Decker T, et al. Extracorporeal shock wave therapy in the treatment of lateral epicondylitis. J Bone Joint Surg [Am] 2002;84:1982-91.

38 Crowther A, Banister $G$, Huma $H$, et al. A prospective randomised study to compare extracorporeal shock wave therapy and injection of steroid for the treatment of tennis elbow. J Bone Joint Surg $[\mathrm{Br}]$ 2002;84:678-9.

39 Melikyan EY, Shahin E, Miles J, et al. Extracorporeal shock wave therapy for tennis elbow. A randomized double blind study. J Bone Joint Sur [Br] 2003;85:852-5.

40 Rompe J, Decking J, Schoellenr C, et al. Repetitive low energy shock wave treatment for chronic lateral epicondylitis in tennis players. Am J Sports Med 2004;32:734-43. 
41 Melegati G, Tornese D, Bamdi M, et al. Comparison of two ultrasonographic localization techniques for the treatment of lateral epicondylitis with extracorporeal shock wave therapy: a randomized study. Clinical Rehabilitation 2004;18:366-70.

42 Gam AN, Thorsen H, Lonnberg F. The effects of low-level laser therapy on musculoskeletal pain: a meta analysis. Pain 1993;52:63-6.

43 Smidt N, Assendelft W, Arola H, et al. Effectiveness of physiotherapy for lateral epicondylitis: a systematic review. Ann Med 2003;35:51-62.
44 Trudel D Duley J Zastrow I et al Rehabilitations for patients with lateral epicondylitis: a systematic review. J Hand Ther 2004;17:243-66.

45 Moher D, Pham B, Jones A, et al. Does the quality of reports of randomized controlled trials affect estimates of intervention efficacy reported in metaanalysis? Lancet 1998:352:609-13.

46 Van Tulder MW, Assendelft WJJ, Koes BW, et al. Method guidelines for systematic reviews in the Cochrane Collaboration Back Review Group for spinal disorders. Spine 1997;22:2323-30.

\section{ELECTRONIC PAGES}

\section{Online original articles}

$\mathrm{T}$ he following electronic only articles are published in conjunction with this issue of BJSM (see also pages 158 and 165 )

\section{Relation between foot arch index and ankle strength in elite gymnasts: a preliminary study}

S T Aydog, L Özçakar, O Tetik, et al

Background: Gymnasts usually start intensive training from early childhood. The impact of such strenuous training on the musculoskeletal system is not clear.

Objectives: To evaluate the relation between muscle strength of the ankle joint and foot structure in gymnasts.

Methods: The study population comprised 20 high level male gymnasts and 17 non-athletic healthy male controls. Arch indices were measured using a podoscope. Ankle plantar/dorsiflexion and eversion/inversion strengths were measured using a Biodex 3 dynamometer within the protocol of concentric/concentric five repetitions at $30 \%$ velocity.

Results: The mean arch index of the right and left foot of the gymnasts and the controls were respectively: 31.4 (29.1), 34.01 (34.65); 60.01 (30.3), 63.75 (32.27). Both the arch indices and the ankle dorsiflexion strengths were lower in the gymnasts. Although no correlation was found between strength and arch index in the control group, a significant correlation was observed between eversion strengths and arch indices of the gymnasts $(r=0.41, \mathrm{p}=0.02)$.

Conclusions: Whether or not the findings indicate sport specific adaptation or less training of the ankle dorsiflexors, prospective data are required to elucidate the tendency for pes cavus in gymnasts, for whom stabilisation of the foot is a priority.

(Br J Sports Med 2005;39:el3) http://bjsm.bmjjournals.com/ cgi/content/full/39/3/el3

\section{Long term outcomes of inversion ankle injuries A Anandacoomarasamy, L Barnsley}

Background: Ankle sprains are common sporting injuries generally believed to be benign and self limiting. However, some studies report a significant proportion of patients with ankle sprains having persistent symptoms for months or even years.

Aims: To determine the proportion of patients presenting to an Australian sports medicine clinic who had long term symptoms after a sports related inversion ankle sprain.

Methods: Consecutive patients referred to the NSW Institute of Sports Medicine from August 1999 to August 2002 with inversion ankle sprain were included. Exclusion criteria were fracture, ankle surgery, or concurrent lower limb problems. A control group, matched for age and sex, was recruited from patients attending the clinic for upper limb injuries in the same time period. Current ankle symptoms, ankle related disability, and current health status were ascertained through a structured telephone interview.

Results: Nineteen patients and matched controls were recruited and interviewed. The mean age in the ankle group was 20 (range 13-28). Twelve patients (63\%) were male. Average follow up was 29 months. Only five (26\%) ankle injured patients had recovered fully, with no pain, swelling, giving way, or weakness at follow up. None of the control group reported these symptoms $(p<0.0001)$. Assessments of quality of life using short form-36 questionnaires (SF36) revealed a difference in the general health subscale between the two groups, favouring the control arm $(p<0.05)$. There were no significant differences in the other SF36 subscales between the two groups.

Conclusion: Most patients who sustain an inversion ankle injury at sport and who were subsequently referred to a sports medicine clinic had persistent symptoms for at least two years after their injury. This reinforces the importance of prevention and early effective treatment.

(Br J Sports Med 2005;39:el4) http://bjsm.bmjjournals.com/ cgi/content/full/39/3/el4 